As a result of this survey a number of previously accepted ideas concerning the aetiology of ulcer are discountenanced, further evidence is adduced in favour of others and some new facts emerge. Thus there is no evidence that bus drivers, shift workers or those who have irregular meals show an increased incidence of ulcer. Many gastro-enterologists have thought that gastric and duodenal ulcer are different diseases and it is shown that there is considerable reason for believing this to be so; the relative morbidity differs according to social classes, at different ages and in the two sexes. It is shown that whereas class differences do not affect the development of duodenal ulcer, the incidence of gastric ulcer increases as the social scale is descended. Agricultural workers develop peptic ulcers less often than expected, whereas duodenal ulcer is found more commonly among doctors than in other members of the same social class. It is, however, believed that the latter depends upon the more accurate appreciation of the significance of melaena by members of the medical profession and not upon a true increase in morbidity. The evidence shows that anxiety over work is associated with duodenal ulcer, and it is suggested that this association is more likely to depend upon a common constitutional factor than the direct effect of worry in causing ulcer. Whatever the explanation, the man who worries over his job is more likely than his neighbours to develop a duodenal ulcer, and the lowest paid worker, unless he is lucky enough to be an agricultural labourer, stands the greatest chance of getting a gastric ulcer. For the whole population under survey, 6.5 per cent. of the men and 1.7 per cent. of the women were ulcer subjects, and 24.9 per cent. of the men and 27.8 per cent. of the women had 'other dyspepsias.'

The detailed nature of this painstaking enquiry makes it impossible to summarize it fully in a short review. Anyone interested in the subject should read it for himself. Apart from the information about peptic ulcer, it is a model of statistical research. It is a truism that ' anything can be proved by statistics,' and while this is an obvious exaggeration, it is a weak point of many investigations of this kind that the conclusions drawn from the figures, significant though they may be, are not always valid. The obvious explanation of a significant difference in behaviour between a number of groups is not always the correct one. The authors have in this case taken every care to avoid drawing false conclusions from the figures and have done their best to check possible sources of error.

R.S.B.P.

\section{ETERNAL EVE}

By Harvey Graham. Pp. xx +699 , illustrated. London: William Heinemann. r950. 42s.

This book is difficult to read but even more difficult to review. It lacks the appeal of the author's 'Surgeons All,' and the enthusiasm and power of Howard Haggard's 'Devils, Drugs and
Doctors,' though it contains chapters, such as 'The Glory that was Rome' and 'Rabbits and Quacks' that display Dr. Graham's lucid and attractive style at its best.

This is an enormously long book, which does not seem to have gained in value in proportion to its length. The book is also somewhat disjointed in narrative, but it is impossible to escape from the fact that Dr. Graham has read widely and with discernment. He has packed in a mass of factual information, but the whole work leaves the reader unsatisfied. . It is likely to confuse the layman, and he who might lay it aside part finished would command sympathy. The medical historian on the other. hand will miss the detailed bibliography that such a work surely merits. The extra pages would add little in length, but much in value to the historian. If it is really designed for lay consumption, drastic reduction in length would be a great advantage.

In a book such as this it is a great joy to see many original and carefully chosen illustrations.

$$
\text { G.B.L. }
$$

\section{ST. THOMAS'S HOSPITAL REPORTS, Vol. VI}

Pp. 285, illustrated. London: St. Thomas's Hospital. 1950. 10s. $6 \mathrm{~d}$.

This is an interesting and valuable collection of articles and reports from all departments of the hospital, outlining new work, describing current practice or reporting series of cases.

It would be invidious as well as impossible for any reviewer to single out individual articles from so wide a field, but reviews of 490 cases of carcinoma of the bronchus, of 485 cases of cancer of the large bowel and of 3 I cases of Addison's disease obviously give much material for thought; whilst a study of the results of ligation of the spermatic cord in the repair of inguinal hernia, though only concerned with ro cases, none the less provides good reason for condemning the procedure.

\section{HOW I CURED MY DUODENAL ULCER}

\section{By John Parr. Pp. r6o. London: Michael} Joseph Ltd. 1951. 8s. 6d.

This little book is the life history of Mr. John Parr's duodenal ulcer which the owner has finally managed to cure with the aid of a special diet. There is also a reasonably clear and sensible account of the various theories of the aetiology of this condition. One can only hope that Mr. Parr continues to have no further trouble with his ulcer, but at the same time one must remain sceptical as to whether the treatment he advocates is really the best treatment for all cases of duodenal ulceration. No doubt this little book will sell well, particularly amongst laymen, but it is a little difficult to see that it will serve any useful purpose. 